\title{
Author Index Volume 6 (2012)
}

The issue number is given in front of the pagination

Anastassakis, G. and T. Panayiotopoulos, A unified model for representing objects with physical properties, semantics and functionality in virtual environments (2) 123-137

Anggarani, R. and J. Watada, A gasoline consumption model based on the harmony search algorithm: Study case of Indonesia (3) 233-241

Antunes, C.H., see Dias, L.C. (4) 243-244

Antunes, C.H., see Dias, L.C. (4) 245-264

Bauer, Jr., K.W., see Leap, N.J. (1) 1-25

Bigaret, S., see Meyer, P. (4) 283-296

Bliss, J.P., R. Liebman and J.C. Brill, Alert characteristics and identification of avatars on a virtual battlefield (2) 151-159

Brill, J.C., see Bliss, J.P. (2) 151-159

Castro, J.R., see Martínez, L.G. (1) 59-67

Chorbev, I., B. Joksimoski and D. Mihajlov, SA Tabu Miner: A hybrid heuristic algorithm for rule induction (4) 265-271

Christia, P., see Tsolis, D. (2) 97-104

Clare, A.S., P.C.P. Maere and M.L. Cummings, Assessing operator strategies for real-time replanning of multiple unmanned vehicles (3) 221-231

Cococcioni, M., E. D’Andrea and B. Lazzerini, One day-ahead forecasting of energy production in solar photovoltaic installations: An empirical study (3) 197-210

Cummings, M.L., see Clare, A.S. (3) 221-231

Czyzewski, A., see Kupryjanow, A. (2) 177-185

Czyzewski, A., see Lech, M. (2) 161-169

D’Andrea, E., see Cococcioni, M. (3) 197-210

de Carvalho, V.O., see dos Santos, F.F. (1) 43-58

Dias, L.C., C.H. Antunes and D.R. Ínsua, Guest editorial (4) 243-244

Dias, L.C., C.H. Antunes and D.R. Insua, Dealing with uncertainty in Decision Support Systems: Recent trends (2000-2011) (4) 245-264 dos Santos, F.F., V.O. de Carvalho and S.O. Rezende, Improving hierarchical document cluster labels through candidate term selection (1) 43-58

Ínsua, D.R., see Dias, L.C. (4) 243-244

Insua, D.R., see Dias, L.C. (4) 245-264

Joksimoski, B., see Chorbev, I. (4) 265-271

Kampana, S., see Tsolis, D. (2) 97-104

Kaszuba, K. and B. Kostek, A new approach for automatic assessment of a neurological condition employing hand gesture classification (2) 171-176

Katagiri, H., see Uno, T. (1) 69-75

Kato, K., see Uno, T. (1) 69-75

Körnefors, R., see Stigmar, M. (2) 113-121

Kostaras, N. and M. Xenos, Usability evaluation of Augmented Reality systems (2) 139-149

Kostek, B., see Kaszuba, K. (2) 171-176

Kostek, B., see Lech, M. (2) 161-169

Kupryjanow, A. and A. Czyzewski, Improved method for real-time speech stretching (2) 177-185

Lazzerini, B., see Cococcioni, M. (3) 197-210

Leap, N.J. and K.W. Bauer, Jr., A confidence paradigm for classification systems with out-of-library considerations (1) 1-25

Lech, M., B. Kostek and A. Czyzewski, Virtual Whiteboard: A gesture-controlled pen-free tool emulating school whiteboard (2) 161-169

Licea, G., see Martínez, L.G. (1) 59-67

Liebman, R., see Bliss, J.P. (2) 151-159

Lourenço, J.M. and P.J. Santos, Short-term load forecasting using a Gaussian process model: The influence of a derivative term in the input regressor (4) 273-281

Madduma, B. and S. Ramanna, Image retrieval based on high level concept detection and semantic labeling (3) 187-196 
Maere, P.C.P., see Clare, A.S. (3) 221-231

Mallawarachchi, Y., see Ratnayake, R.M.N.N. (3) 211219

Marikar, F.M.M.T., see Ratnayake, R.M.N.N. (3) 211219

Martínez, L.G., J.R. Castro, A. Rodríguez-Díaz and G. Licea, Decision making fuzzy model for software engineering role assignment based on fuzzy logic and big five patterns using RAMSET (1) 59-67

Meyer, P. and S. Bigaret, Diviz: A software for modeling, processing and sharing algorithmic workflows in MCDA (4) 283-296

Mihajlov, D., see Chorbev, I. (4) 265-271

Oommen, B.J., see Qin, K. (1) 27-41

Pagden, N., see Stigmar, M. (2) 113-121

Panayiotopoulos, T., see Anastassakis, G. (2) 123-137

Qin, K. and B.J. Oommen, The entire range of Chaotic pattern recognition properties possessed by the Adachi neural network (1) 27-41

Ramanna, S., see Madduma, B. (3) 187-196

Ratnayake, R.M.N.N., Y. Mallawarachchi, D. Tennakoon and F.M.M.T. Marikar, Treatment planning for supracondylar fracture in humerus in children by image processing (3) 211-219

Rezende, S.O., see dos Santos, F.F. (1) 43-58

Rodríguez-Díaz, A., see Martínez, L.G. (1) 59-67
Santos, P.J., see Lourenço, J.M. (4) 273-281

Schworm, S. and K.D. Stiller, Does personalization matter? The role of social cues in instructional explanations (2) 105-111

Shimony, S.E., see Tolpin, D. (4) 297-304

Stigmar, M., R. Körnefors and N. Pagden, The modified role of university teachers in ICT-supported flexible learning (2) 113-121

Stiller, K.D., see Schworm, S. (2) 105-111

Tennakoon, D., see Ratnayake, R.M.N.N. (3) 211-219

Tolpin, D. and S.E. Shimony, Rational value of information estimation for measurement selection (4) 297-304

Tourtoglou, K. and M. Virvou, An Intelligent recommender system for trainers and trainees in a collaborative learning environment for UML (2) 7995

Tsolis, D., P. Christia and S. Kampana, OWLearn: An open source e-learning platform supporting adaptivity and personalization (2) 97-104

Uno, T., H. Katagiri and K. Kato, A Stackelberg solution for fuzzy random competitive location problems with demand site uncertainty (1) 69-75

Virvou, M., see Tourtoglou, K. (2) 79-95

Watada, J., see Anggarani, R. (3) 233-241

Xenos, M., see Kostaras, N. (2) 139-149 